\title{
Mental Health \& Community Mental Health in Nepal: Major Milestones in the development of Modern Mental Health Care
}

\author{
Dr. Kapil Dev Upadhyaya \\ Senior Psychiatrist, Kathmandu Model Hospital \& Advisor, CMC-Nepal \\ E-mail *Corresponding author: drkapilupadhyaya@gmail.com
}

Keywords: History, Psychiatry, Nepal

Bir Hospital, the first general hospital with specialist services was established in the country in 1889 A.D. When I came back to Nepal after MBBS in 1971, most of the specialties like Medicine, Surgery, Gynae \& Obs, Opthalmology, ENT, Psychiatry, Anesthesiology, Radiology, Emergency department with 24 hours service were there. Paediatric OPD service was available, and children were admitted in Kanti children hospital Kathmandu. So mental health service in Nepal was started in a general hospital with different specialties.



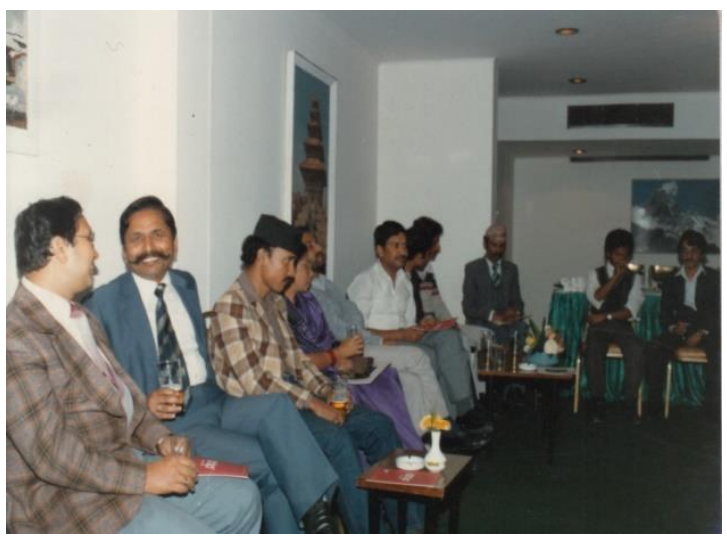

(Dr. Bishnu Prasad Sharma, the first psychiatrist Picture 1 \& Dr. Desh Raj Bahadur Kunwar second psychiatrist. Picture 2.)

In 1961 A. D. Psychiatric out patient service in Bir hospital was started by Dr. B. P Sharma \& in 1965, 5 -bedded inpatient psychiatric unit was started in this hospital, bed strength was increased to 12, in 1971. Psychiatric services was started in Tri-Chandra Military hospital (Est.1925 AD) Kathmandu in 1976 by Dr. D.R.B. Kunwar1 for the army personnel and their families. It had inpatient facility of 10 beds initially. Psychiatric inpatient and outpatient department of Bir Hospital was shifted to Lagankhel and became a first and central level 
Mental Hospital in 1984, with 25 inpatient facility. Other doctors working in this Hospital were Dr. Priambada Khanal, Dr. Dhruba Man Shrestha, Dr. Kajal Chakravarti, Dr. B.B. Sharma and Dr. Ambika shrestha . Mental Hospital was actually shifted to the old buildings of Lalitpur district hospital. The present buildings were constructed after demolishing the old structures. Tri-Chandra Military hospital was shifted to Tahachal Kathmandu as Royal Army Hospital, which is now medical college teaching hospital. It is worth remembering that from 1961 to 1981, there were only 2 psychiatrists in the country. Dr. D.M. Shrestha came in 1982, Dr.N.M.Shrestha in 1985, Dr. M.K. Nepal in 1986 and thus no. of psychiatrists started increasing in the country.

It is noteworthy that there were no large custodial mental hospitals in Nepal and Nepalese mental patients used to go to Ranchi Mental hospital, or Gorakhpur or Lucknow for treatment of mental disorders. Faith healing, Homeopathy, Ayurbedic medicine, naturopathy were other means of treatment, which are popular now also. In Ayurbeda, psychiatry is called Bhutvidhya, a disturbance of spirit.

Dhulikhel Jail was the place where psychotic male patients with or without criminal background were kept. And such female patients were kept in Central jail in Kathmandu. I have visited several times to Dhulikhel Jail to see these patients and once in central jail to see female patients. Since past many years, Ministry of Home Affairs allocates budget for prescribed medicines. Conditions in jail was pitiable in 1980s, gradual improvement in space, food and other facilities are seen now.

NGO sector started rehabilitation centre for Nepali drug abuser in 1976. Cannabis smoking in young generation was common, and increased more with the coming of Hippies and other western tourists. A few drug users of injectable pethidine, Morphine, Buprenorpine were there. Later on heroine chasing and injecting became a public health problem. Many NGO's with rehabilitation centers opened to manage drug users both in Kathmandu and major cities of the country. However, numbers of drug users seemed exaggerated, as same client was counted in Biratnagar, Pokhara, Dharan, Kathmandu etc, wherever he was taken to treatment due to repeated relapses.
NGO's started working in the field of intellectual disability in 1983/84. Many parents of mentally retarded children do not like their children leveled as a mental health problem, intellectual disability is a developmental condition and not a disease.

Community mental health programme as a pilot project was started in Lalitpur district through community health development project (CDHP) in 1984. Community mental health programme in Nepal is based on the 5 years evaluation report of this programme. This will be discussed in detail later.

Psychiatric outpatient services were started at the T.U. Teaching Hospital Kathmandu in 1986, and inpatient service in 1987 by Dr. MK Nepal later joined by Dr. VD Sharma. Dr. N.M. Shrestha, Dr. Kajal Chakravarti and Dr. B.B. sharma joined mental hospital as a psychiatrist. In the Tri-chandra Military hospital Dr. DRB Kunwar \& Dr. Krishna Chandra Rajbhandari were the psychiatrist. I came back from NIMHANS Bangalore after completing my DPM in 1987, but decided to go to Western Regional Hospital Pokhara to start the psychiatric services there, first time outside Kathmandu Valley in government hospital. During my training, I had seen the community psychiatry activity in one of the Karnataka district near Bangalore. Prof. R. Srinivasa Murthy and additional Prof. Mohan K. Issac and their team were working in community psychiatry. I was motivated to work in the community in addition to hospital services.

In 1988, I started psychiatric out-patient service in western Regional Hospital Pokhara. Initially, hospital doctors and nurses were in the opinion that mental health problems are hardly there in that area. For many days, I used to sit in my OPD without any patient. At times, I used to see OPD patients in medicine or paediatric department when there was too much rush. International Nepal Felloship (INF) was also working jointly in that hospital, one general surgeon, one orthopedic surgeon, one ENT surgeon and a senior nurse were the expatriate medical staffs in addition to other staffs. They started referring patient to my OPD. I started to teach Pokhara Nursing Campus students covering their course in medicine, raising their 
awareness in epilepsy and common mental health problems and started receiving referral cases from the field visits of nursing students . WHO -Nepal office used to give financial support for mental health training for doctors and other health professionals. A mental health training for doctors and nurses of western region was organized by Dr D.M. Shrestha, then the director of mental hospital. Medical superintendent of WRH Dr. R.R. Upadhyaya was highly supportive in the development of psychiatry in that hospital.


( Dr. R.R. Upadhyaya - Med.superintendent), Dr. K. S. Rana, Dr. Kajal Chakrvarti, Dr. D.M. Shrestha \& participants of mental health training and trainers in Pokhara. Picture -3 \&4)

\section{Community Mental Health}

\section{Programme:}

Mental health project (MHP) was established with the financial support of INGO's in
Kathmandu in the year 1989. Its office was in the TUTH compound, and project director was Dr. M.K. Nepal. As far I know, United Mission to Nepal (UMN) and Red Barna were the financial partners, but there may be other partners also. MHP was carrying out various activities, out of which one major activity was community mental health. MHP started community mental health programme in one of the district (Morang) in eastern Nepal in 1991, maximum no. of epilepsy cases were detected in Morang. I do not know other details about this programme. MHP started community mental health programme in Kaski in western Nepal with the financial support of UMN through MHP. As I worked in community mental health programme of western region for many years, I am writing this article based on my personal experience.

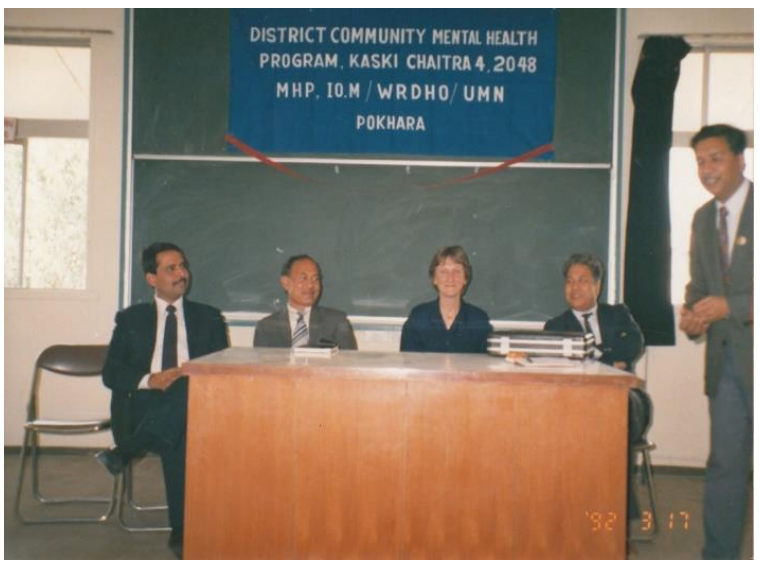

(Dr. M.K. Nepal, Dr. Benu Bahadur Karki Western Regional Director, Dr. Chris Wright, Dr. I.P. Pradhan-W.R. Hospital Superintendent in the inauguration of Community $\mathrm{MH}$ Programme in Picture 5)

MHP started community mental health programme in one of the district (Kaski ) in western Nepal in the year 1992. Dr. Chris Wright of U.K. was the Director of Mental health programme of UMN Kathmandu. She has contributed a lot in the development of mental health in Nepal. She was hard working, with clear cut vision, plan and creative ideas. She was strict during working hours, but very friendly at other times. Without her vision and without financial support of UMN we would not have 
developed in mental health, particularly in the formulation of mental health policy and in community mental health . Before starting community mental health programme, a pilot programme of community mental health was carried out in Lalitpur district for 5 years and the programme was evaluated, and a paper was also published by Wright $C$ et al2 Based on the pilot project evaluation report whose conclusion was " The community Mental Health of C.D.H.P. appears to offer a workable model of Community Mental Health services which is replicable", community mental health programme was started in Nepal. The community programme is also based on saying of a very senior psychiatrist, experienced in community mental health Prof. N.N. Wig " awareness that mental health service does not necessarily need to be provided by highly trained people but could also be delivered by the ordinary health workers3 . Prof. Wig was coordinator of the first mental health programme in India. He was invited as a keynote speaker in the National Seminar on Community Mental Health -1994 in Kathmandu. His speech was enlightening and this seminar was well organized, well participated and one of the major step in the development of mental health in Nepal.

Dr. B.B. Karki supported community mental health programme, when he was Regional Health Director. He was the person who was given the responsibility to develop final organogram of doctors of the country. He asked me about the post of psychiatrists and the needs of the country. At that time, there were two first class and two second class psychiatrist posts in mental hospital and there were no other posts. As psychiatry was not considered an important specialty, in the draft proposal only second class posts in all major hospitals outside Kathmandu was there. He agreed to keep first class posts like in other major specialties, in all referral hospitals, when I told him," who will study a neglected subject like psychiatry when there are no oppurnities for career ladder development". Luckily same organogram was accepted by the Ministry of Health.

Dr. M.K. Nepal was the person who developed psychiatry department in TUTH, started MD Psychiatry programme and along with Chris Wright, contributed in community mental health programme. There were some psychiatrists who did not want to start MD psychiatry in TUTH. Is it necessary? Is it possible? like questions came. I was in one of the meeting where Prof. D. Mohan from AIIMS was invited to discuss about this issue. Luckily MD Psychiatry residency programme was started. Main credit goes to Dr. M.K. Nepal and Dr. Chris Wright.

In 1995, Drug Abuse Demand Reduction Project (DADRP) was started with the support of UNDCP in Kathmandu. MHP started community mental health programme in one of the district (Banke ) of mid-western region. But Banke community programme was closed after about two years, I do not know the reason. Morang community programme was going well with many case detection especially epilepsy and depression. Kaski community mental health programme (1st phase) was extended to the neighboring district Syangja in 2nd phase. Later this community mental health programme was upgraded to Western Regional Community Mental Health Programme (WRCMHP) in 3rd phase with further extension to many districts. Regional office was in Pokhara with the aim of expanding the services in the western region further. Mr. Klass Jan Pol from UMN was posted there in the regional office. This expansion was possible as UMN was supporting it through MHP. Dr Sarah Acland, psychiatrist of UMN supported western region community mental health programme in our training and supervision work for many years. She was one of the pillars for the running and success of western region mental health programme. Dr Acland was also the chief of UMN mental health programme when Dr C. Wright left UMN. 


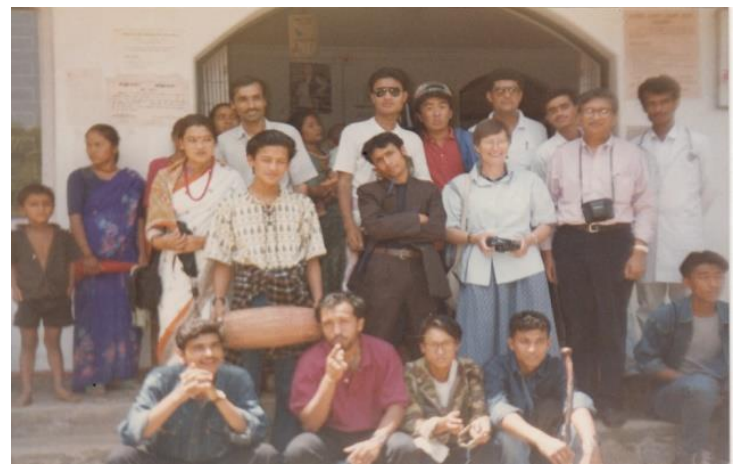

(Dr. Sarah Acland with the street Drama artists and Video recording team in Waling Bazar Syanza. picture-6)

Street Drama for common mental disorders like depression, psychosis, alcoholism and other problems like epilepsy, and Intellectual disability, was shown by professional artists of Pokhara after several rehearsals and this show was recorded by experts from UMN, and later we used this video during training of health workers. This was one of the awareness raising activities in the community.

In the similar way as a part of awareness raising, case detection and stigma reduction activities, mental health camp and mental health exhibition (pamphlets, posters, flipchart, reading materials) was organized in Walling bazaar of Syangja and Ghandruk village of Kaski4, epilepsy, depression and chronic psychosis were the main cases seen in such camps. Preinformation regarding camps in advance in coordination with district health office and local PHC/ Health post and the local clubs are necessary for the success of such camps.

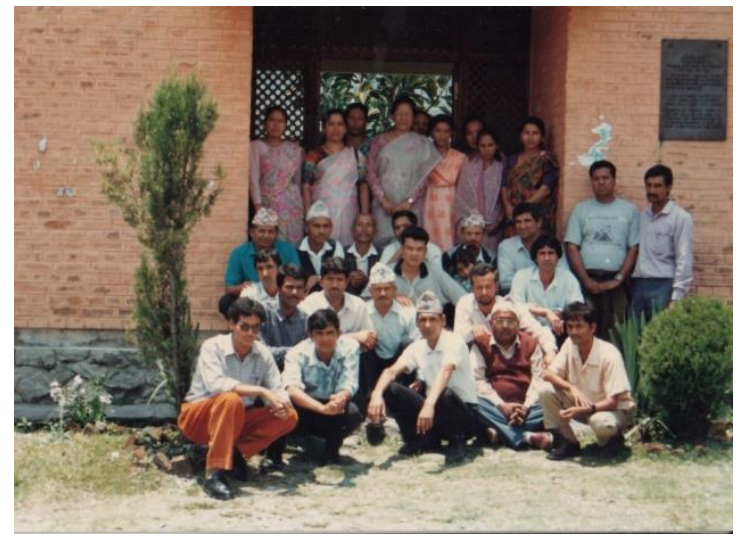

(Ms. Maiya Ranjitkar with Health assistants, AHWs and ANMs. Picture-7)

Ms. Ranjitkar was the senior public health administrator of Kaski, very energetic and supportive to community mental health in Kaski. This group received mental health block training of 10 days duration. They were trained to diagnose, common mental disorders, and refer to hospital when necessary. A referral to psychiatrist and back referral to the health worker was developed, so that they could do the follow-up and gain confidence to deal with mental disorders. We continued to give such mental health block trainings for many groups, either in Kathmandu where excellent training manpower mainly the psychiatrists, and psychologists were available or in Pokhara for which some trainers were invited from Kathmandu. We also used to conduct refresher training of three days to strengthen mental health skills of the health workers.

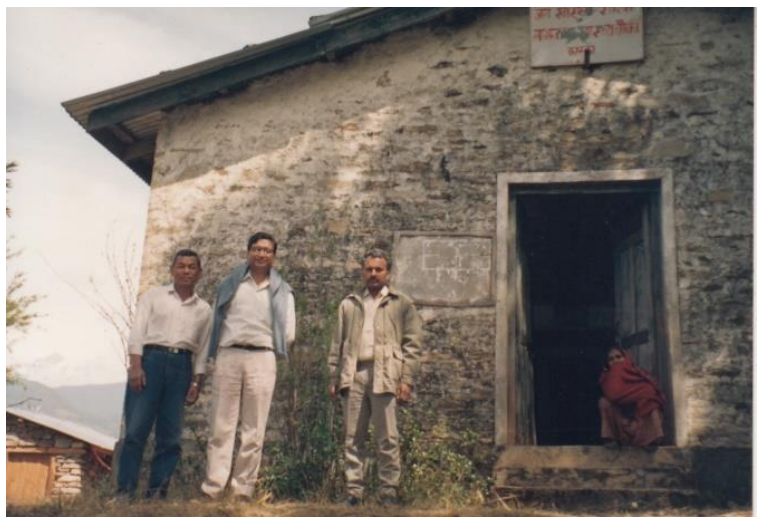

This is one of the health post in Kaski (picture 8) , I am with the trained health assistant, during supervision visit to their mental health activities. I also used to see mental disorder cases who came for treatment in such places during supervision visit.

During mental health block training, Depression including dysthymia and post partum depression, Psychosis both acute and chronic type, Bipolar disorder, Anxiety neurosis (GAD), Conversion disorder, generalized tonic clonic epilepsy (GTCS) and alcoholism were the major topics to be covered. Other topics were active 
listening and communication skills, Intellectual disabilty, \& psychosexual problems. A special form was developed to check the symptoms of different mental disorders. Trained person had to ask certain leading questions to the client mentioned in this form and mark in it. This marking helped them for provisional diagnosis. During training each participant had to see certain no. of cases, take history, do short mental status examination, fill the given form and make provisional diagnosis. It was noticed that in clear cut cases diagnosis of depression, epilepsy and anxiety neurosis was easier, where as diagnosis of psychosis, bipolar disorder, conversion disorder and alcohol dependence was difficult. Refresher training and follow up of psychosis cases improved their confidence to deal with psychosis and schizophrenia cases. CMC-Nepal still uses this form in its community mental health programme. Government of Nepal, department of health

Large number of health workers right from health assistant (HA), AHWs, Nurses, Junior health workers, maternal and child health workers, and FCHVs were trained. Local traditional healers and police were also trained. Major thrust of training was on recognition and referral to proper places for diagnosis and treatment. HA and AHWs were trained for 10 days and others for just a day or so. It helped a lot in awareness raising, stigma reduction and improved the treatment seeking behavior.

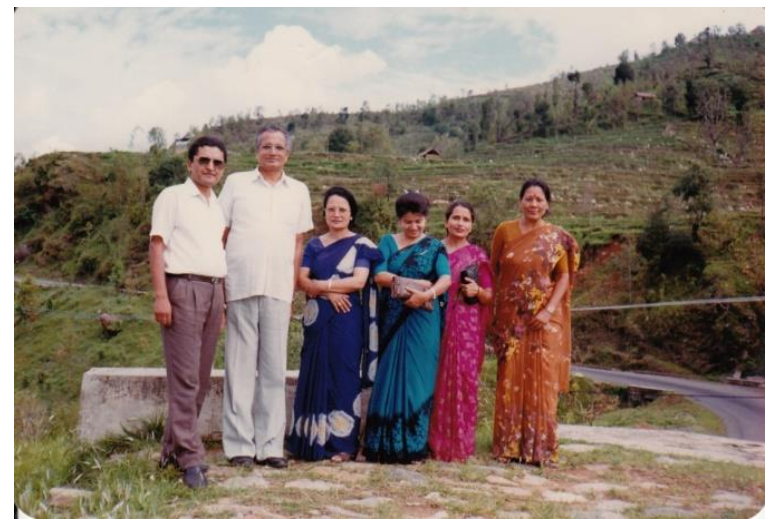

( Dr. R.N. Sinha, Dr. N.H. Kharel, Metron S. Tuladhar \& Asst. Metron D. Sharma ( WRHospital), Mrs Kharel and Ms Maiya Ranjitkar in picture -9)
Dr. R.N. Singha the regional health director supported mental and dental health by organizing 3 days mobile camp in Damauli of Tanahun, and Syanza of Syanza district. Unfortunately, I did not keep the data of these camps to mention here, camps were organized before starting community mental health programme of Kaski. Free medicines were supplied for one to three months and patients were advised to come to hospital for follow-ups if they needed long term medication. These mobile dental and mental health camps were organized to provide services as well as to raise awareness in mental and dental health. Dr. N.H. Kharel is the dental surgeon. I would like to remember Dr Sinha, because it was a new initiative by a regional director in mental health. Dr. Yesobardhan Pradhan during his tenure as Regional Health Director also supported mental health activities and my work in the community mental health. As we were working and training govt. health staffs, without the active support of regional health director and district public health officer, community activities in mental health was not possible.

Kaski Community mental health programme (1992-93) was extended to Syanza district in the second phase (1993-1996). In 1996 this programme was evaluated by Additional prof. of Psychitry Mohan K. Issac of NIMHANS Bangalore and Retd. Director General of Health services Dr. R. N. Sinha 5. They recommended extension of programme in other districts and advised to perform several short research activities, active effort to raise community awareness, make available of essential drugs for treatment of epilepsy, and depression and make further effort to find cases in the community. Thus the programme was further extended to third phase (1997-2000). Some short research activities were carried out like:

(1)Epilepsy at four Kaski village health posts, Nepal. Journal of Institute of Medicine vol.4, 55th issue Oct. - Dec. 1996 (pp 137 - 143)

(2) Suicide in Kaski District, Nepal, Journal of Institute of Medicine vol.20 no. $3 \& 4,59$ th issue Jul - Sep/Oct-Dec 1998.

(3) A mental Health Prevalence survey in two developing towns of western region, Journal of the Nepal Medical association vol.42 No.150, Nov. - Dec. 2003, pp 328-330. 
(4) Traditional healers of Nepal and Faith healing. Proceedings of National Seminar on Implementation of National Mental Health Policy: \& Symposium on " Alternative Approaches to Mental Health Service" June 22, 1999 (pp 156 -167).

(5) Socio-demographic profile of psychoactive substance users in Pokhara Valley, Journal of the Nepal Medical Association, vol. 39, No. 136, Oct. - Dec 2000; pp 332 - 337.

(6) Morbidity profile of patients attending Neuropsychiatric OPD at the Western Regional Hospital Pokhara, Journal of the Nepal Medical Association Vol 38, No. 131 July - September

In 1999, this programme was again evaluated by external evaluators ( Dr. Deepa Braganza, dr. Tjerk H Nap 6. Input from many UMN staffs like Dr. Sarah Acland Psychiatrist, Ms. Raija Kiljunen Psychologist, Ms. Baby Nakarmi Psychiatric nurse, Krishna Adhikari and Shree krishna Shrestha are notable. Input from MHP especially Dr MK Nepal and Dr. VD Sharma was equally important. Large no. of other personnels especially from regional directors office, district public health office, district hospitals and PHC staffs, and different levels of health workers of western region were important. FCHVs and faith healers of the community helped by referring cases to the health facilities. Many lessons were learnt by working in this programme.

\section{First PAN Conference:}

First national Conference of Psychiatrists Association of Nepal was organized by Dr. Sudhir K. Khandelwal Prof. of Psychiatry and Head BPKIHS Dharan and his team. PAN executives and we almost all the psychiatrists of Nepal attended this conference. This was a historical event in mental health and for PAN. Conference was very well organized and many psychiatrists, and neurologists from AIIMS Delhi and other places were there. Details of the conference may be seen in the Abstract Book \& Souvenir 13-14 November 1998. I would like to quote two messages from this souvenir, one from Prof. N.N.Wig "Three great resources which exist in abundance in Nepal : the strong family ties; deep-rooted cultural traditions, and network of primary health care services extended to remote areas". Other message is from Prof. Shiv Gautam -“ The Association will equip itself to face the challenges like development of specialty of psychiatry, creating public awareness, destigmatisation of mental illness, protection of human rights of mentally ill and getting psychiatry its due status through teaching, research and quality patient care". Though there may be nothing new in these messages, they summarize what needs to be done at the community level and at the institutional level by mental health professionals, particularly by the new generations.

\section{Miscellanies:}

In the year 1986, when Dr. K.C. Rajbhandhari and I were doing our residency in National Institute of Mental Health and Neurosciences (NIMHANS) Bangolore, King Birendra visited this institute (picture -10). We were happy that the king will take interest in the development of mental health in Nepal.

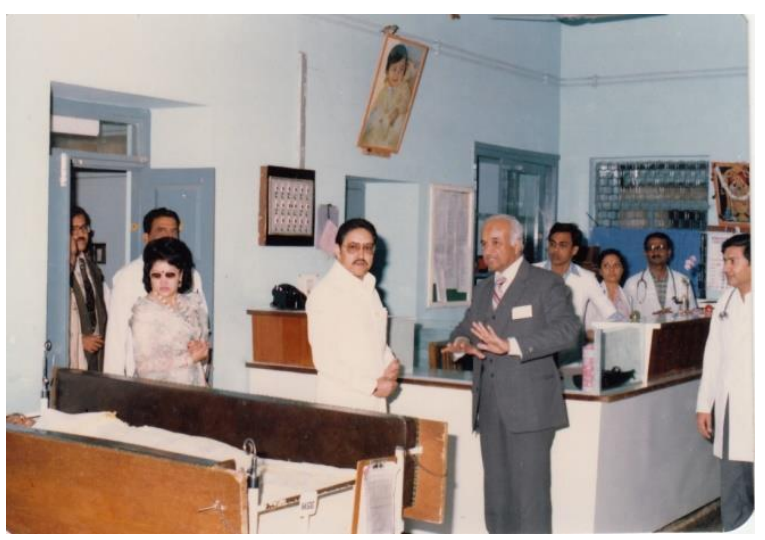

Just to break monotonous reading of the article, Dr. M.K.Nepal, Dr. C. Wright and I were attending Social Psychiatry conference in Hongkong. We saw good rehabilitation center and occupational therapy activities of treated psychotic patients in remission. Mostly, packaging work, appeared suitable to them. 


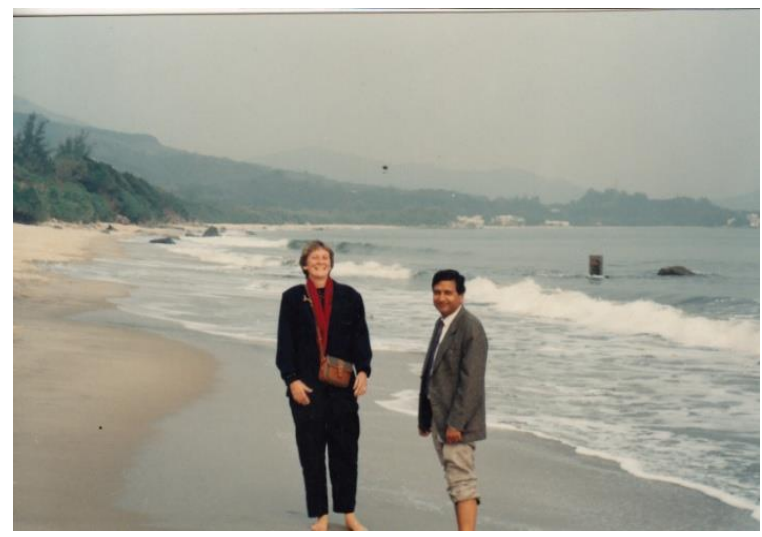

This picture is one of the popular Island of Hongkong, where we went after attending the conference. Dr. C Wright and me (picture-11).

Whatever I have written is based on my personal experience and memory. In Many pictures, I am also there not because of my intentions but due to my collections. Many other significant people have contributed in the work that I have mentioned like, TUTH Staffs, MHProject staffs, UMN Staffs, Driver, Western Regional community mental health staffs, Regional health directorate staffs, all the staffs who came for training, and the patients. I would like thank them all for their support. Aim of writing this article is for the history of mental health in Nepal for the new generations. Psychiatry has become a fast growing specialty in Nepal. I hope that quality mental health service will also expand in the same way.

\section{REFERENCE:}

1. Development of mental health services in Nepal and challenges in New millennium. D.R.B. Kunwar; Presidential address, Souvenior First National Conference of Psychiatrists association of Nepal pp11-12

2. Wright c, Nepal M K, Bruce Jones W, (1989) Mental Disorders in Primary Health Care Services in Nepal: Asia Pacific Journal of Public Health 3 (3) 224-230.

3. Report of the National Seminar on Community Mental health: Model or Myth? Milestones to Maturity 1994; $p-8$
4. Proceedings of National seminar on Implementation of National mental Health Policy: Accelerating the Rate and meeting the Challenges edited by Dr. MK Nepal, Dr. VD Sharma Dr. NR Koirala June 22, 1999.

5. Issac. MK \& Singha, RN (1996) Evaluation of Western Region Community Mental Health Services

6. Braganza, D and Nap. T.J. (1999) Evaluation of mental health programme of United Mission to Nepal 